\title{
Computer-Aided Surgical Simulation for Correcting Complex Limb Deformities in Children
}

\author{
Leonardo Frizziero ${ }^{1, *} \mathbb{D}$, Gian Maria Santi ${ }^{1} \mathbb{D}$, Alfredo Liverani $\left.{ }^{1} \mathbb{(}\right)$, Francesca Napolitano ${ }^{1}$, \\ Paola Papaleo ${ }^{1}$, Elena Maredi ${ }^{2}$, Giovanni Luigi Di Gennaro ${ }^{2}$, Paola Zarantonello ${ }^{2} \oplus$, \\ Stefano Stallone ${ }^{2}$, Stefano Stilli ${ }^{2}$ and Giovanni Trisolino ${ }^{2}$ \\ 1 Department of Industrial Engineering, Alma Mater Studiorum University of Bologna, 40136 Bologna, Italy; \\ gianmaria.santi2@unibo.it (G.M.S.); alfredo.liverani@unibo.it (A.L.); \\ francesca.napolitan5@studio.unibo.it (F.N.); paola.papaleo2@studio.unibo.it (P.P.) \\ 2 IRCSS-Istituto Ortopedico Rizzoli (Rizzoli Ortopaedic Institute), Paediatric Orthopaedics and \\ Traumatology, 40136 Bologna, Italy; elena.maredi@ior.it (E.M.); giovanniluigi.digennaro@ior.it (G.L.D.G.); \\ paola.zarantonello@ior.it (P.Z.); stallone.stefano@gmail.com (S.S.); stefano.stilli@ior.it (S.S.); \\ giovanni.trisolino@ior.it (G.T.) \\ * Correspondence: leonardo.frizziero@unibo.it
}

Received: 24 May 2020; Accepted: 23 July 2020; Published: 28 July 2020

\begin{abstract}
This work aims to present an in-house low-cost computer-aided simulation (CASS) process that was recently implemented in the preoperative planning of complex osteotomies for limb deformities in children. Five patients admitted to the Unit of Paediatric Orthopaedics and Traumatology from April 2018 to December 2019, for correcting congenital or post-traumatic limb deformities were included in the study. Three-dimensional (3D) digital models were generated from Computed Tomography (CT) scans, using free open-source software, and the surgery was planned and simulated starting from the 3D digital model. 3D printed sterilizable models were fabricated using a low-cost $3 \mathrm{D}$ printer, and animations of the operation were generated with the aim to accurately explain the operation to parents. All procedures were successfully planned using our CASS method and the 3D printed models were used during the operation, improving the understanding of the severely abnormal bony anatomy. The surgery was precisely reproduced according to CASS and the deformities were successfully corrected in four cases, while in one case, the intraoperative intentional undersizing of the bone osteotomy produced an incomplete correction of a congenital forearm deformity. Our study describes the application of a safe, effective, user-friendly, and low-cost CASS process in paediatric orthopaedics (PO) surgery. We are convinced that our study will stimulate the widespread adoption of this technological innovation in routine clinical practice for the treatment of rare congenital and post-traumatic limb deformities during childhood.
\end{abstract}

Keywords: 3D modeling; surgical simulation; computer aided; preoperative planning; paediatric orthopaedics; surgery; osteotomy

\section{Introduction}

Computer-aided surgical simulation (CASS) is becoming an increasingly important means of improving skills acquisition, optimizing clinical outcomes, and promoting patient safety in orthopaedics and traumatology [1]. The combination of computer-aided design (CAD), three-dimensional (3D) printing technology, and mixed (virtual/augmented) reality is emerging as the cutting edge, opening new horizons in surgery. While there have been great strides in other fields of surgery [2], CASS is in its relative infancy within paediatric orthopaedics (PO). PO often deals with the surgical treatment of congenital or acquired limbs and spine deformities during infancy. PO surgery aims to restore 
function, improve aesthetics, and ensure proper residual growth of limbs and spine, using osteotomies, bone grafts, age-specific or custom-made hardware and implants. Despite the fact that several bone deformities are simple and their treatment is straightforward, complex rare deformities are frequently encountered in PO. Complex deformity is defined as occurring in at least two planes (e.g., shortening, angular, and rotational deformity), sometimes involving two or more bones (i.e., forearm deformities that involve both ulna and radius). This type of surgery usually requires extensive preoperative planning, because of the complex 3D anatomy of the axial and appendicular skeleton. Growing evidence has proven that CASS may increase performance, precision, and efficiency of surgeons, thus, decreasing complications and adverse outcomes, and driving down costs for both patients/families and health care system [3-7]. However, CASS is often considered as costly, time consuming, and the prerogative of a few specialized centers that have facilities and trained staff for it, thus, discouraging its use among surgeons. These limitations have recently motivated the use of open-source software and user-friendly low-cost technology [8].

This work summarizes the preliminary results of a CASS process that was recently implemented at a tertiary referral center for paediatric orthopaedics and traumatology, through a close collaboration with a university department of industrial engineering. We aimed to assess the feasibility and effectiveness of an in-house low-cost CASS process in paediatric orthopaedic surgery.

\section{Materials and Method}

\subsection{Study Design and Case Series}

The present study is a pilot of an ongoing prospective research aimed at developing, refining, and implementing in clinical practice specific CASS tools and processes, in the field of PO surgery. All subjects gave their informed consent for inclusion before they participated in the study. The study was conducted in accordance with the Declaration of Helsinki, and the protocol was approved by the "Area Vasta Emilia Centro" Ethics Committee (CE-AVEC. Project identification code: 3D-MALF-356/2018/Sper/IOR). Children presenting with congenital or post-traumatic deformities of the limbs requiring corrective osteotomies who were admitted at the Unit of Paediatric Orthopaedics and Traumatology from April 2018 to December 2019 were included in the study. Patients who did not sustain corrective osteotomies of the long bones (i.e., soft tissue procedures or bone resection without realignment procedures), patients who received other types of correction (i.e., growth modulation, distraction/osteogenesis by circular external fixation, or limb lengthening by intramedullary telescopic nail), or patients who did not own Computed Tomography (CT) scans in the proper format were excluded. The CASS process was accomplished according to the surgeons' preferences and experiences, thus, the study was not randomized and patients were not consecutive. Parents and carers gave consent for the study.

\subsection{From $C T$ to $3 D$ Digital Model}

A conversion procedure was applied to transform the CT scan into a 3D model [9]. CT scans in a digital imaging and communications in medicine (DICOM) format were imported to the imaging software InVesalius v3.1 (CTI: Center for Information Technology "Renato Archer", Campinas SAO, Brazil, 2017) [10] and rendered to generate virtual reconstructions of the selected structures. Care was taken in setting the right density range, in order to highlight the specific region and create the 3D model, eliminating unnecessary anatomical parts. The use of Invesalius, generated 3D surfaces in standard triangulation language (STL). The meshes generated were corrected using MeshLab v2016.12 (ISTI-CNR “Alessandro Faedo", Pisa, Italy, 2016) [11], an open-source software that enables cleaning, remodeling, and remeshing of the structure. The use of MeshLab is essential to make the 3D surface hollow, and consequently, lighter. The structure obtained with MeshLab have holes, cavities, and, in general, imperfections. In order to remove them, another free 3D modeling software called Meshmixer v2017 (Autodesk, San Rafael, CA, USA, 2017) [12] was used. In the end, a Boolean operation 
was performed with Blender v2.8, (Blender Foundation, Amsterdam, The Netherland, 2017) [13] and the actual simulation was carried out in a parametric environment using Creo v6, (PTC-Parametric Technology Corporation, Needham, MA, USA, 2019) [14]. This first part of the reconstruction process was essential to achieve a good geometrical quality and a small amount of faces, in order to allow it to be opened in a parametric CAD without any decrease in performance. The process is summarized in Figure 1.

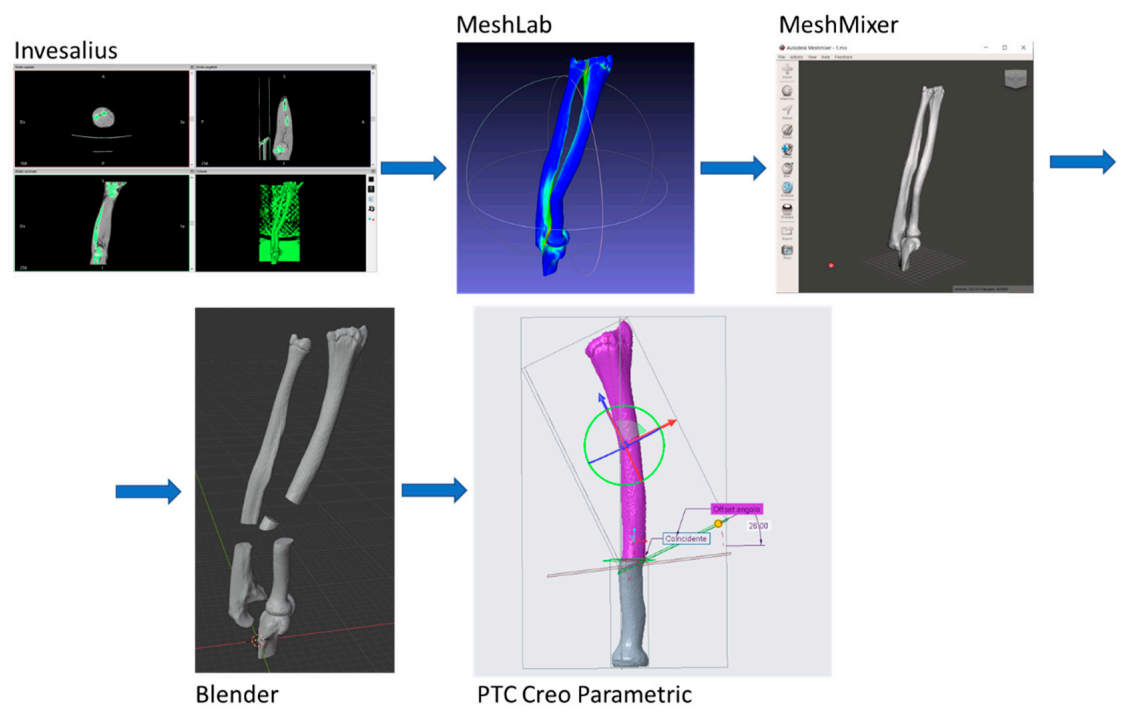

Figure 1. Steps to convert a 2D Computed Tomography (CT) scan to the final 3D simulation.

\subsection{CASS}

The surgery was planned using the 3D generated model. The work consisted of simulating the operation, correcting the alignment, rotation, lengthening of the bones, choosing the level, shape, and direction of the osteotomy, and calculating the size and position of the bone wedge and hardware. Moving from the 3D model, the bony segments were separated using Blender, accomplishing Boolean subtraction at the level of osteotomy. Despite the fact that Blender is not a parametric CAD, the magnitude of approximation error can be tolerated. After the subtraction, all the parts were available to create the assembly, set the right constraints, and simulate the intervention. A reference system was implemented to enable accurate assembly, maintaining the correct relationship among the bony segments. To facilitate the intraoperative reproduction of the planned operation, 3D printed sterilizable models were made using a low-cost 3D printer (EZT3D model T1). The 3D models were printed in high-temperature poly-lactic acid (HTPLA). Furthermore, animations of the operation were generated, with the aim to accurately explain the operation to parents (Figures 2 and 3).

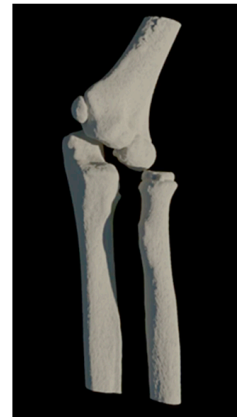

(a)

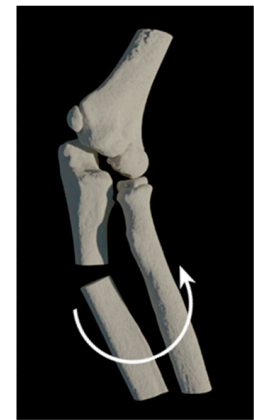

(b)

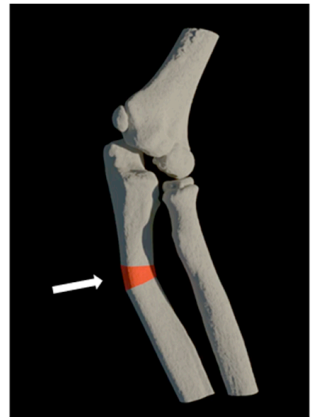

(c)

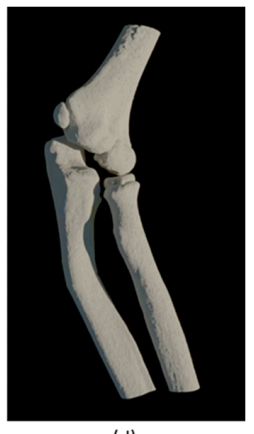

(d)

Figure 2. Video animation of the first case study: (a) initial configuration; (b) cut and rotation; (c) insertion of bone wedge; (d) final result. 


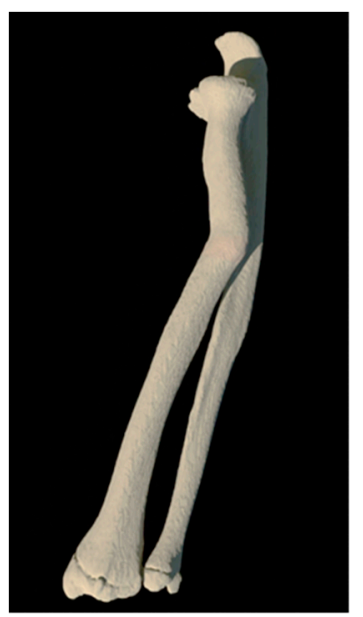

(a)

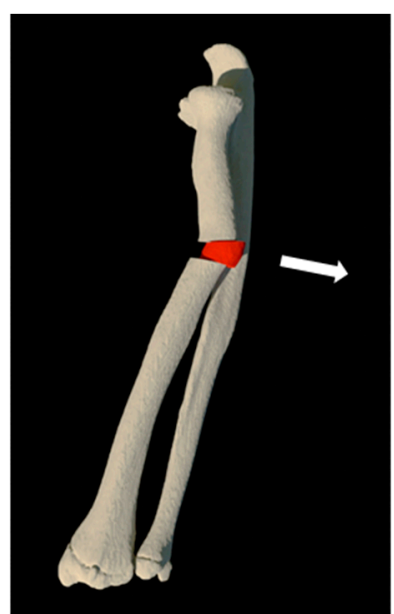

(b)

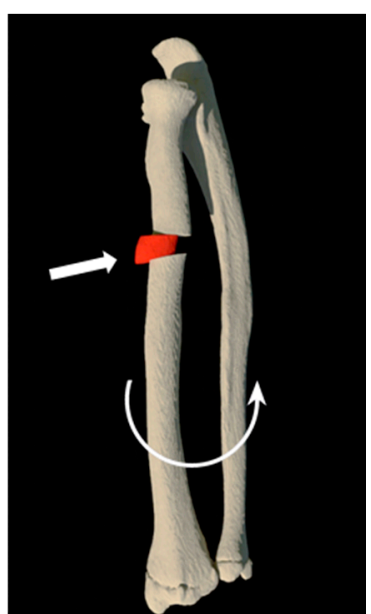

(c)

(d)

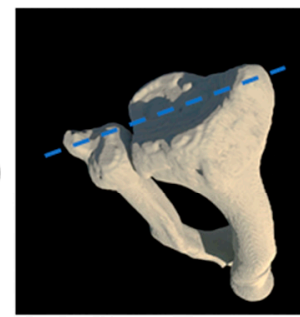

(e)
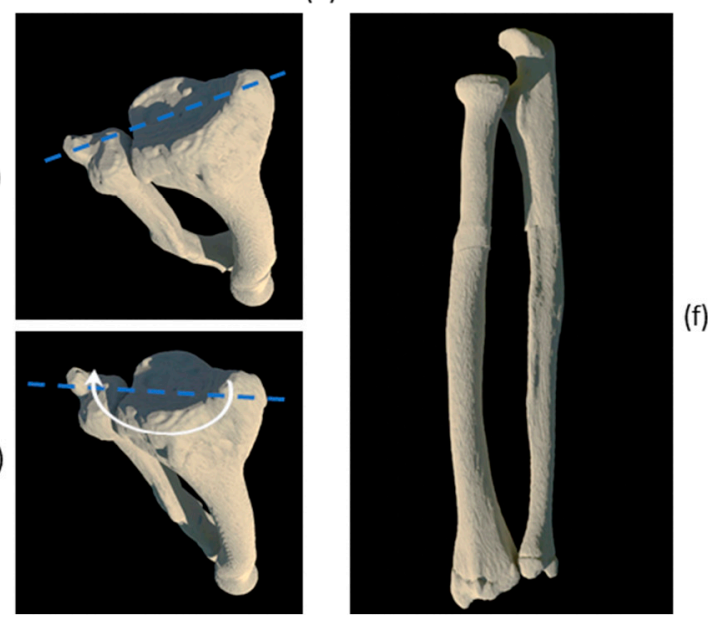

Figure 3. Video animation of the second case study: (a) initial configuration; (b) removal of the bone wedge; (c) rotation and insertion of the bone wedge; $(\mathbf{d}, \mathbf{e})$ axial rotation; (f) final result.

\section{Results}

Five patients were included in the study. The patients' characteristics are described in Table 1. All procedures were successfully planned using our CASS method. The 3D printed models were successfully used during surgery, helping the surgeon to identify the correct landmarks for the osteotomy, accurately modeling and positioning hardware and bone graft when required, and, in general, giving great confidence to the surgeon during the operation. All the operations were performed by two senior surgeons, with 12 years (GT) and 25 years (GLDG) of experience in paediatric orthopaedic surgery, respectively. No complications related to the use of 3D printed models within the surgical field were reported during the operation. Postoperatively, cast immobilization was maintained for 4-8 weeks in all patients but one (case 2, see complete description in Table 1), and then active rehabilitation was recommended. The surgical outcome was assessed on postoperative plain radiographs and it was considered satisfactory if the final correction, as it appeared on the postoperative plain radiographs, matched the planned correction using CASS. The surgery was precisely reproduced according to CASS and the deformities were successfully corrected in all cases but one (case 2). At the latest follow-up, three patients (case 1,3,5) achieved excellent clinical and functional results, although no postoperative outcome scores were used due to the heterogeneity of the case series.

One patient (case 2) affected by focal fibrocartilaginous dysplasia [15] of the forearm, a rare deformity presenting with bowing and shortening of the forearm, loss of pronosupination due to fibrocartilagineous radio-ulnar bridge, dislocation of the radial head, and negative ulnar variance, was planned for corrective surgery by CASS. The surgery, consisting of a corrective closing wedge 
osteotomy of the radius, radio-ulnar bridge excision, bifocal osteotomy of the ulna, and distraction lengthening of the ulna, was performed according to CASS. However, the excised radial wedge was intentionally undersized during the operation to avoid excessive shortening of the forearm and aesthetical issues. Progressive ulnar lengthening ( $45 \mathrm{~mm}$ in 105 days) and early rehabilitation, consisting of passive and active motion of the upper limb, was started two days after surgery. Nonetheless, the insufficient shortening of the radius prevented the lever effect of the distal ulna on the carpus, and consequently, the progressive indirect relocation of the radial head. This induced an incomplete correction of the deformity, with residual negative radio-ulnar variance and persistent dislocation of the radial head. Moreover, the patient developed heterotopic bone formation along the interosseous membrane, requiring further excision.

One patient (case 4) affected by genu varum in Blount disease, reported an initial excellent correction by bifocal osteotomy and bone grafting. Nonetheless, a partial relapse of the deformity was observed at the follow-up visits, therefore, a temporary hemiepiphysiodesis of the tibia was planned during the latest visit.

Table 1. Patient descriptions.

\begin{tabular}{|c|c|c|c|c|c|c|}
\hline No. & $\begin{array}{c}\text { Sex and } \\
\text { Age (years) }\end{array}$ & Diagnose & $\begin{array}{c}\text { Type of } \\
\text { Deformity }\end{array}$ & $\begin{array}{c}\text { Type of } \\
\text { Intervention }\end{array}$ & Complications & $\begin{array}{l}\text { Radiographic } \\
\text { Outcome }\end{array}$ \\
\hline 1 & $\mathrm{~F}, 9$ & $\begin{array}{l}\text { Missed Monteggia } \\
\text { Lesion }\end{array}$ & Post-traumatic & $\begin{array}{c}\text { Proximal ulnar } \\
\text { osteotomy stabilized } \\
\text { with a 6-holes plate }\end{array}$ & None & Corrected \\
\hline 2 & M, 13 & $\begin{array}{c}\text { Focal } \\
\text { fibrocartilagineous } \\
\text { dysplasia }\end{array}$ & Congenital & $\begin{array}{l}\text { Bifocal osteotomy } \\
\text { stabilized with } \\
\text { external fixator }\end{array}$ & $\begin{array}{l}\text { Heterotopic } \\
\text { bone } \\
\text { formations }\end{array}$ & $\begin{array}{l}\text { Fair (residual } \\
\text { dislocation of } \\
\text { the radial head } \\
\text { with shortening } \\
\text { of the ulna) }\end{array}$ \\
\hline 3 & M, 15 & $\begin{array}{l}\text { Post-traumatic } \\
\text { forearm malunion } \\
\text { deformity }\end{array}$ & Post-traumatic & $\begin{array}{l}\text { Bifocal osteotomy } \\
\text { stabilized with } 1 / 3 \\
\text { tubular plate }\end{array}$ & None & Corrected \\
\hline 4 & M, 7 & $\begin{array}{c}\text { Bilateral genu } \\
\text { varum in Blount } \\
\text { disease }\end{array}$ & Congenital & $\begin{array}{l}\text { Double tibial } \\
\text { osteotomy }\end{array}$ & None & $\begin{array}{l}\text { Good (partial } \\
\text { varus } \\
\text { recurrence) }\end{array}$ \\
\hline 5 & $\mathrm{~F}, 6$ & $\begin{array}{c}\text { Coxa vara in } \\
\text { Progressive } \\
\text { Pseudorheumatoid } \\
\text { Dysplasia }\end{array}$ & Congenital & $\begin{array}{l}\text { Valgus derotational } \\
\text { osteotomy }\end{array}$ & None & Corrected \\
\hline
\end{tabular}

Two illustrative cases are reported in Figures 4-7 (case 1) and Figures 8-11 (case 3).
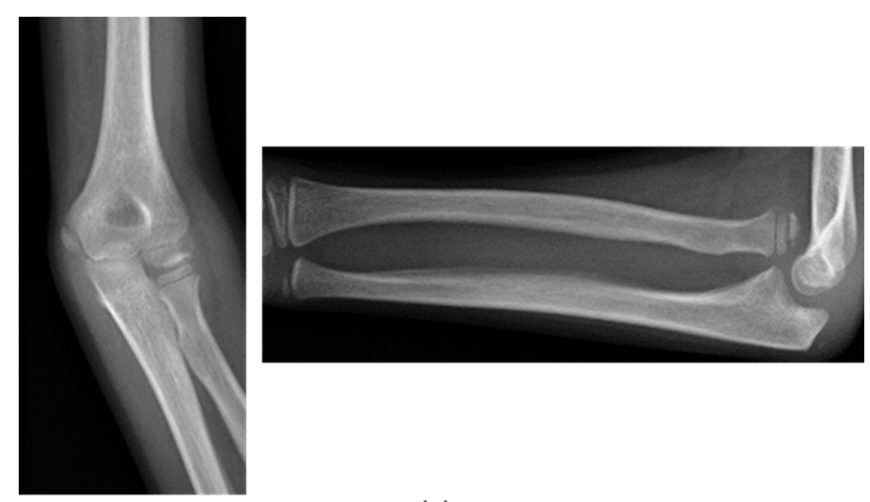

(a)

Figure 4. Cont. 


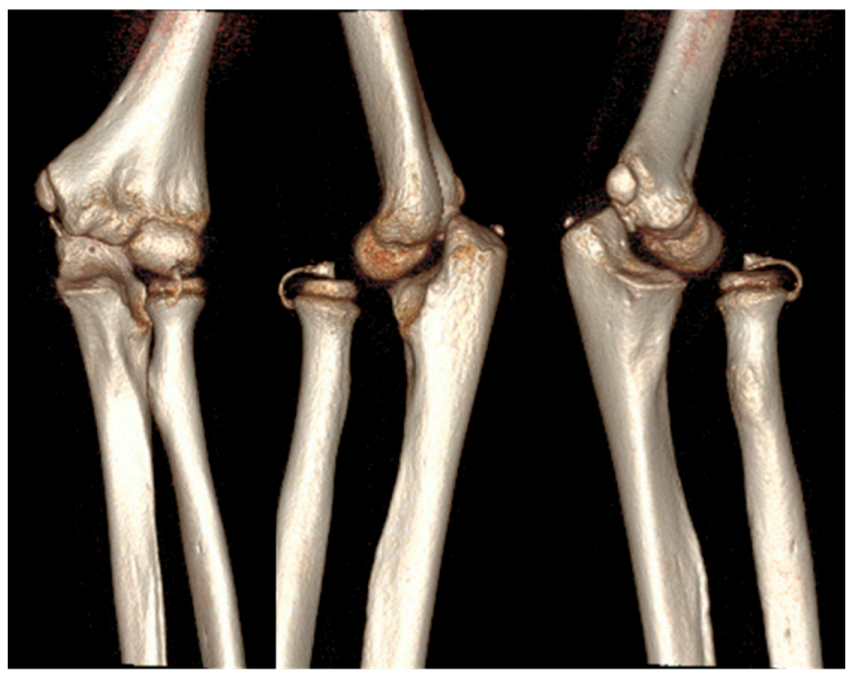

(b)

Figure 4. A nine-year-old girl with a missed Monteggia lesion. (a) Antero-posterior and lateral X-ray; (b) CT scan with 3D reconstruction: the affected elbow showed the typical dislocation of the radial head associated with bowing of the ulna. A cap calcification is visible over the radial head.

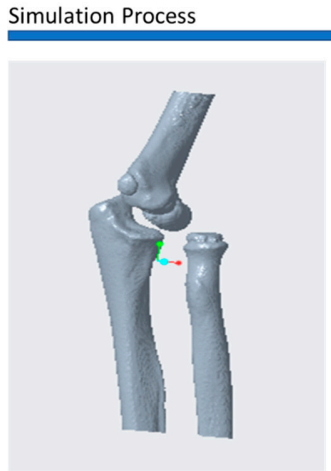

(a)

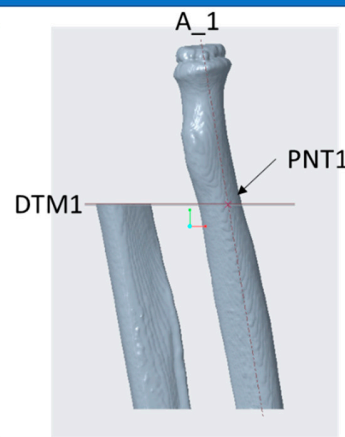

(b)

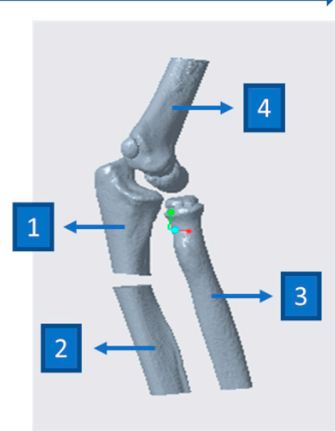

(c)

Figure 5. Simulation process: (a) the reconstructed 3D model is prepared for simulation through the definition of geometrical references; (b) the cutting plane DTM1 meets the axis A_1 defining the rotation point PNT1. DTM1 represents the plane passing through the cutting plane and A_1 is the central axis of a cylinder built on the two bases of the bone; (c) the result of the simulation shows the final position of all 4 pieces (1: proximal part of the ulna; 2: distal part of the ulna; 3 : radius; 4 : humerus).
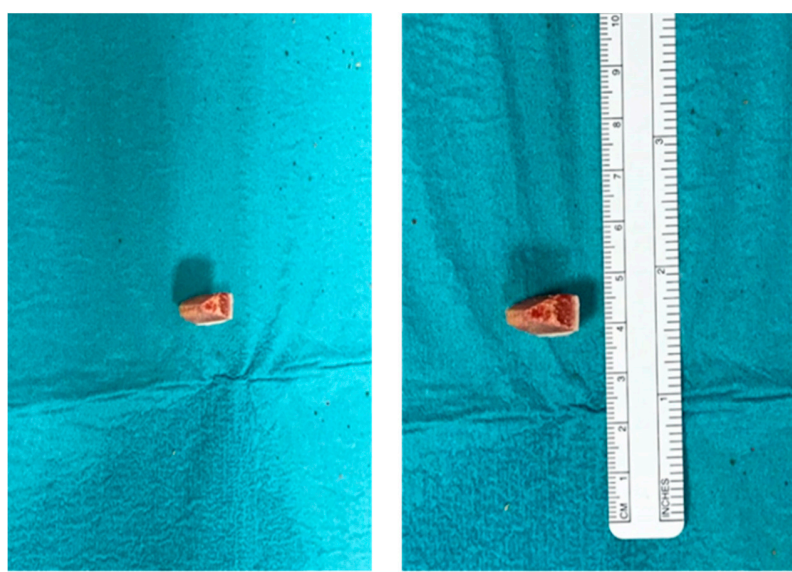

(a)

Figure 6. Cont. 


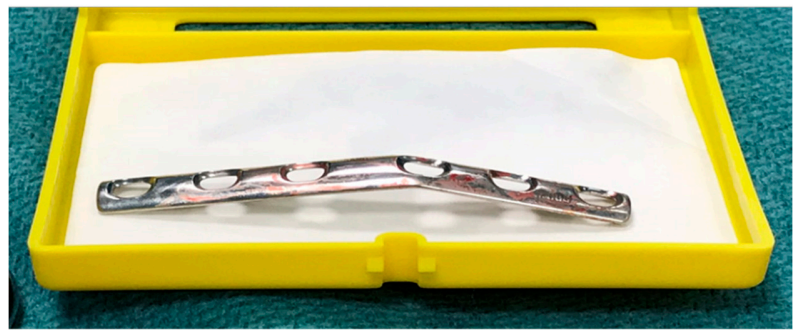

(b)

Figure 6. (a) The bone allograft was cut according to the preoperative simulation; (b) a one-third tubular $3.5 \mathrm{~mm}$ locking compression plate was shaped according to the preoperative simulation.
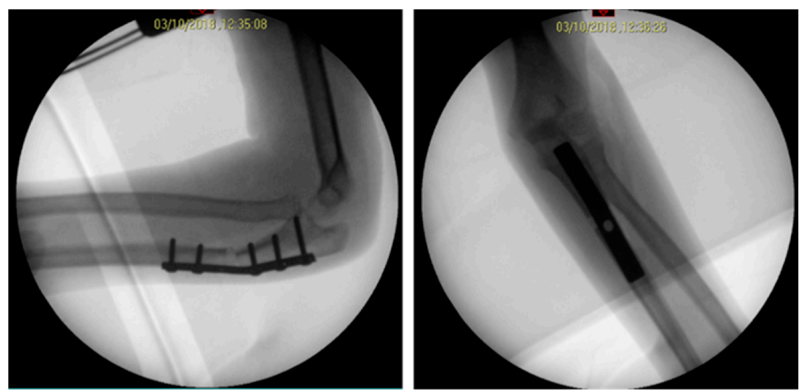

(a)
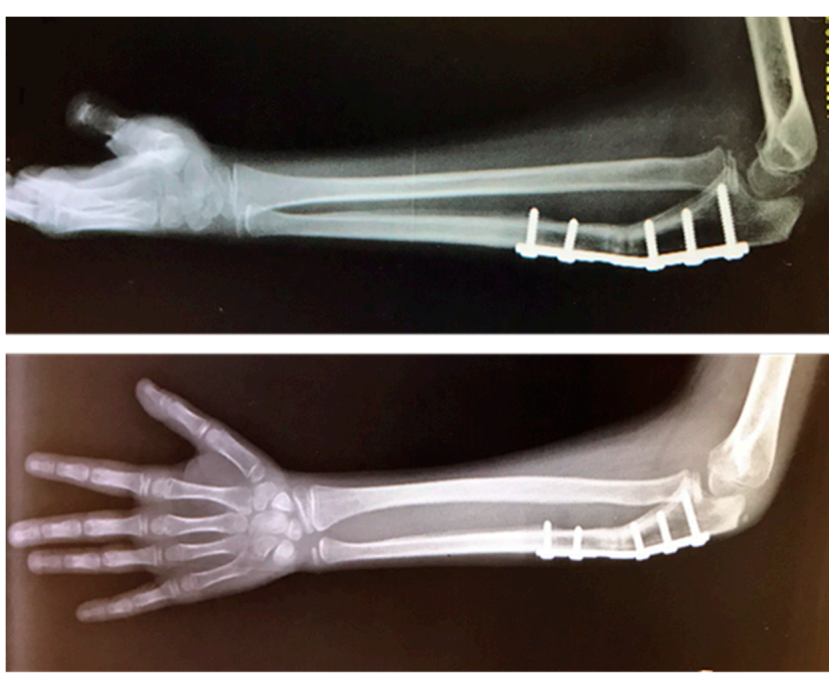

(b)
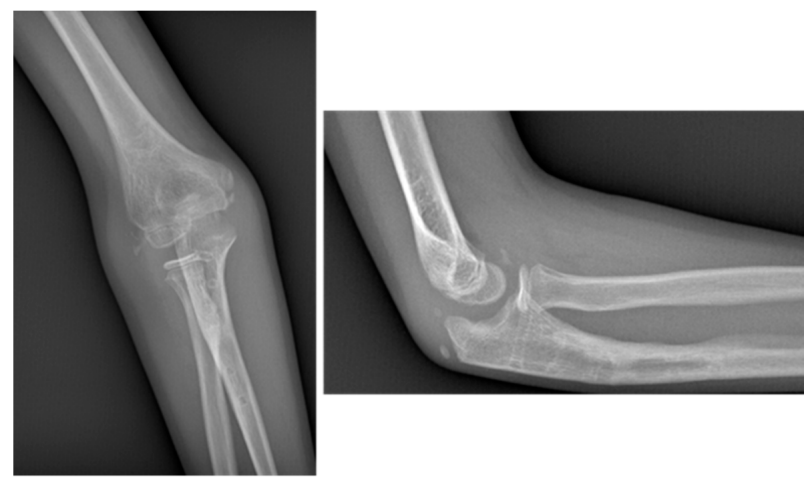

(c)

Figure 7. Antero-posterior and lateral radiographs (a) intraoperative fluoroscopy; (b) at two months of follow-up; (c) after the hardware removal, one year later. 


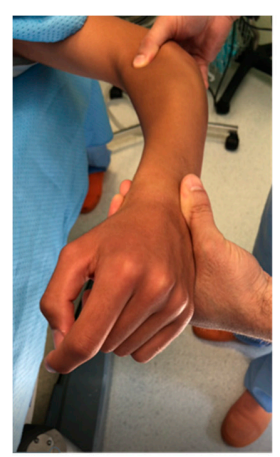

(a)

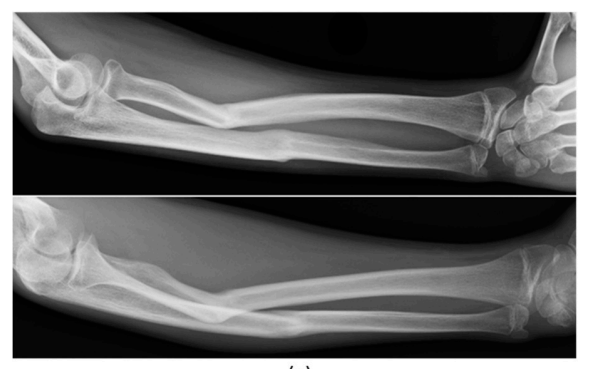

(c)

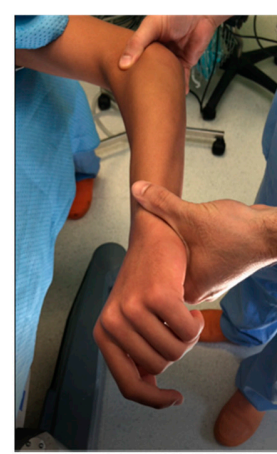

(b)

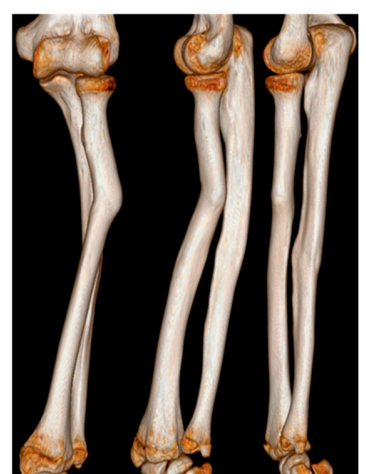

(d)

Figure 8. A fifteen-year-old boy affected by post-traumatic nonunion of the forearm with angular and torsional malalignment of both bones and loss of supination. $(\mathbf{a}, \mathbf{b})$ Preoperative passive range of motion, (c) antero-posterior and lateral radiographs. (d) CT scan with 3D reconstruction.

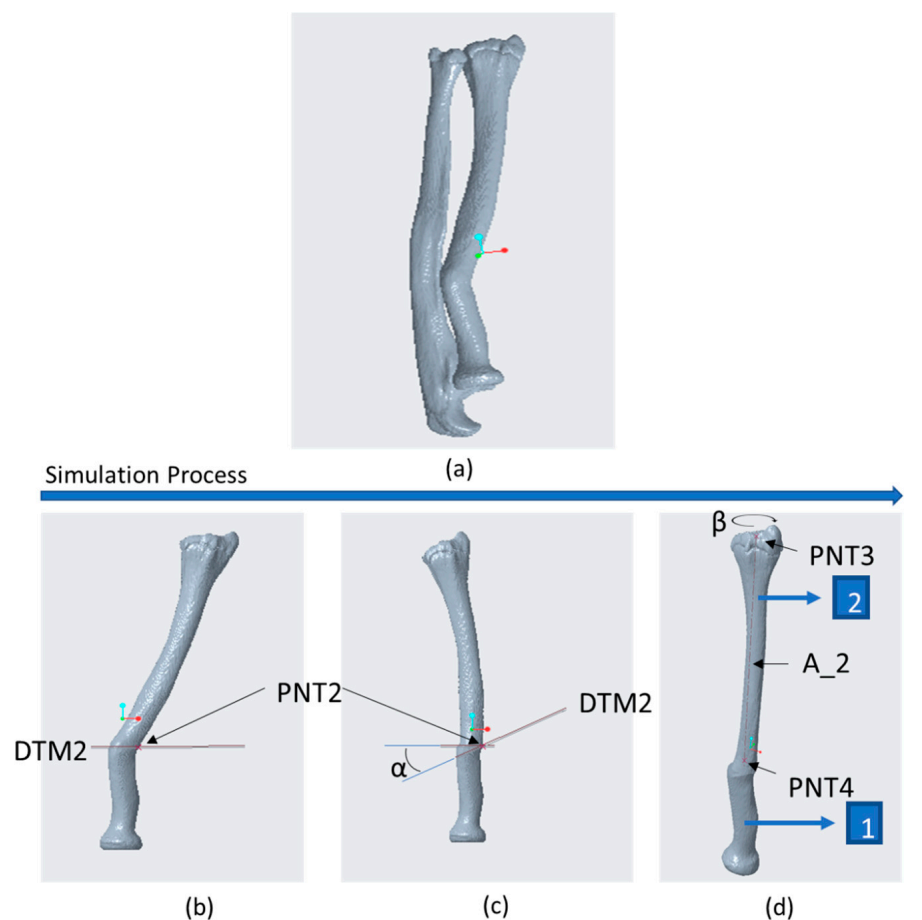

Figure 9. On the basis of the analysis of Miyake [16,17], a new 3D parametric simulation (a) was performed to realign the bones, enabling the achievement of a normal range of motion [18,19]. For the rotational analysis, the cutting plane DTM2 and the rotation point PNT2 were defined. PNT2 stands at the most external edge of the radius on DTM2 (b); the simulation process allowed us to calculate the $\alpha$ angle required to achieve the angular realignment (c); through torsional simulation [20], points PNT3, PNT4, and the resultant axis A_2 were defined. Around the latter a torsion of $\beta=25$ degree was performed to guarantee the optimal configuration of the bone $(\mathbf{d})$. 


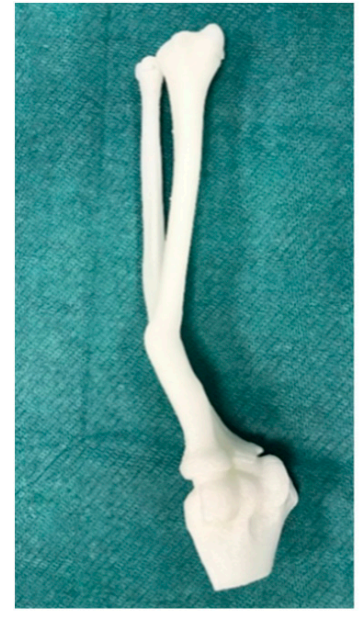

(a)

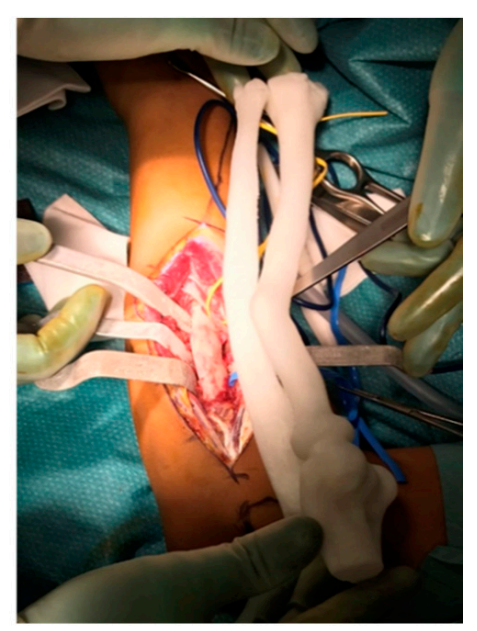

(b)

Figure 10. (a) 3D printed model in sterilizable high-temperature poly-lactic acid (HTPLA). (b) Intraoperative assessment of the bony deformity, by the use of the 3D-printed model. In this case, an accurate preoperative planning allowed the surgeons to choose a unique posterolateral Thompson approach to perform both the osteotomies. The use of a true size sterile 3D-model during the operation allowed the surgeons to overcome the issues related to the limited visualization of the bony segments.

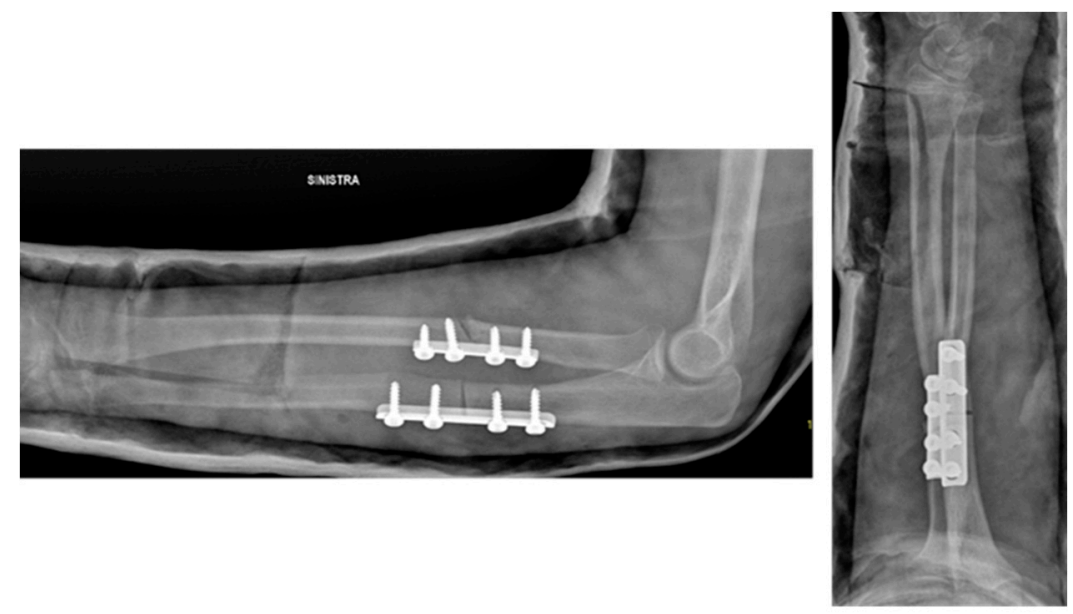

(a)
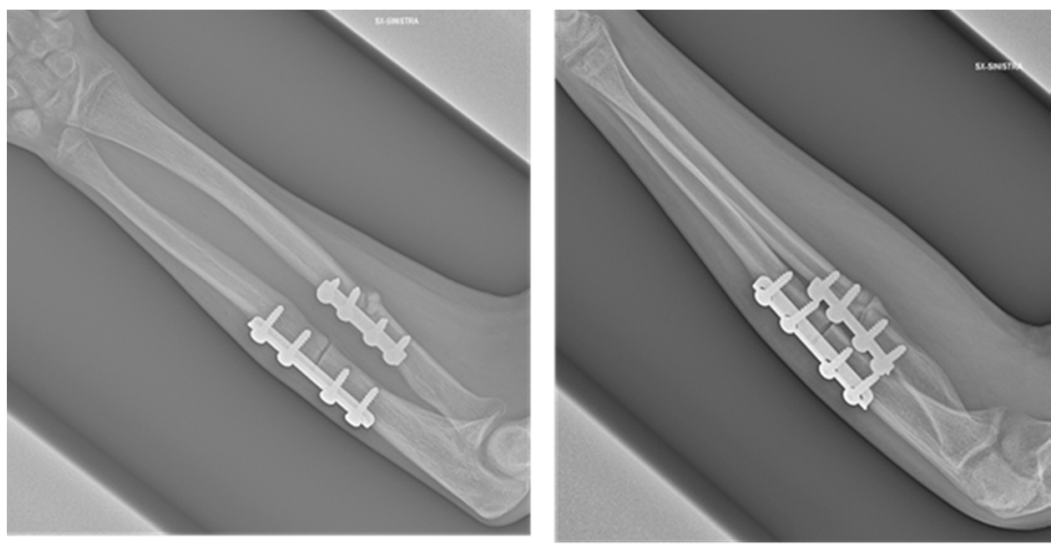

(b)

Figure 11. Cont. 

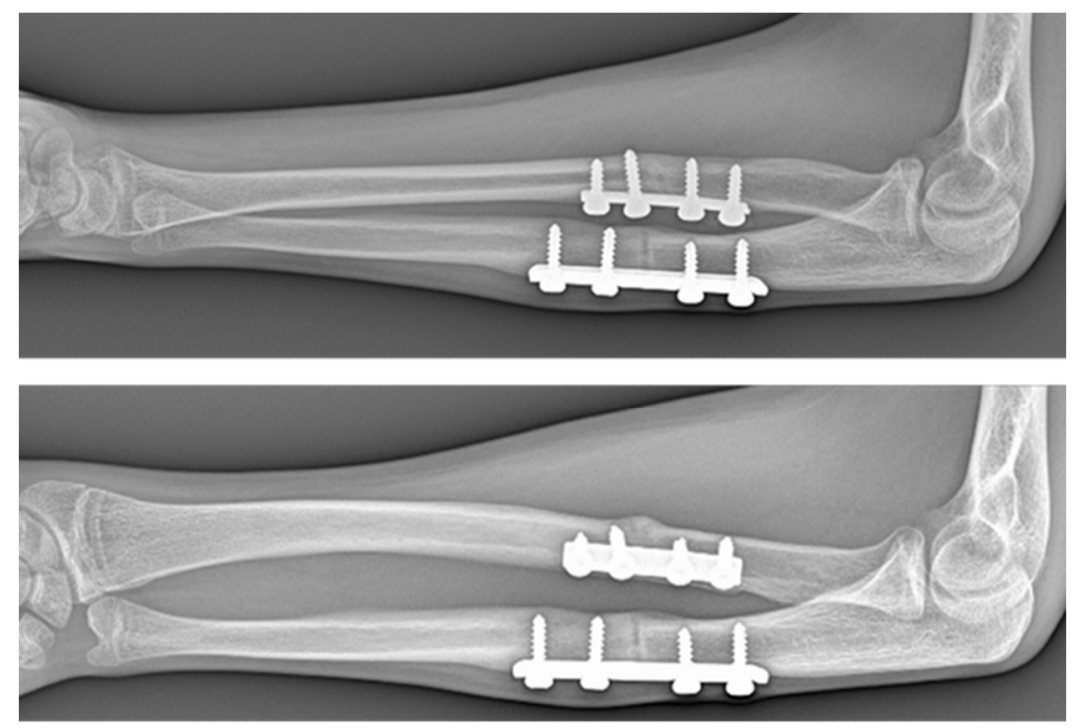

(c)

Figure 11. Antero-posterior and lateral X-Ray of the affected forearm after surgery (a), two months later (b), and at the last control, five months after surgery (c).

\section{Discussion}

The most important result of our study is the development of an in-house CASS process, using open-source or free software and low-cost 3D printing technology as much as possible. Table 2 shows a comparison between our procedure and the most common ones found in the literature.

Table 2. Procedures comparison.

\begin{tabular}{|c|c|c|c|c|c|c|}
\hline Ref. & PROCEDURES & $\begin{array}{c}\mathrm{CT} \\
\text { Reconstruction }\end{array}$ & $\begin{array}{c}\text { 3D } \\
\text { Optimization }\end{array}$ & $\begin{array}{l}\text { Preparation for } \\
\text { 3D Printing }\end{array}$ & $\begin{array}{c}\text { 3D } \\
\text { Simulation }\end{array}$ & Total Cost \\
\hline $\begin{array}{c}\text { OUR } \\
\text { PROCEDURE }\end{array}$ & $\begin{array}{c}\text { Invesalius }+ \\
\text { meshlab/meshmixer + } \\
\text { blender + PTC creo }\end{array}$ & YES (free) & YES (free) & YES (free) & YES & $\begin{array}{l}\text { Only PTC Creo for } \\
\text { 3D simulation }\end{array}$ \\
\hline $\begin{array}{l}\text { Bockhorn et al., } \\
2019[21]\end{array}$ & $\begin{array}{c}\text { ImageJ + Paraview + } \\
\text { MeshMixer }\end{array}$ & YES (free) & $\begin{array}{l}\text { LIMITED } \\
\text { (free) }\end{array}$ & LIMITED (free) & NO & $\mathrm{NO}$ \\
\hline $\begin{array}{l}\text { Perica et al., } \\
2017 \text { [22] }\end{array}$ & $\begin{array}{c}\text { Analyze } 12.0+ \\
\text { Geomagic Wrap }\end{array}$ & YES & YES & YES & $\mathrm{NO}$ & $\begin{array}{c}\text { Analyze 12.0, } \\
\text { Geomagic Wrap }\end{array}$ \\
\hline $\begin{array}{c}\text { Shen et al., } \\
2020 \text { [23] } \\
\text { Huang et al., } \\
2020 \text { [24] }\end{array}$ & Materialise Mimics & YES & YES & YES & $\mathrm{NO}$ & $\begin{array}{l}\text { Materialise } \\
\text { Mimics }\end{array}$ \\
\hline
\end{tabular}

The most common procedure is driven by Materialise Mimics, which is a commercial software, while the others can achieve limited results, since Paraview is mainly a 3D viewer and MeshMixer is not developed as Blender, or they have a commercial price such as Analyze 12 and Geomagic Wrap. In all cases, the other procedures are unable to perform 3D simulation.

In our experience, CASS enabled the successful correction of the limb deformity according to the preoperative planning in four cases, while the only case in which the preoperative simulation was intentionally not reproduced during the operation showed recurrent deformity. These findings are consistent with the current literature, highlighting the effectiveness of computer-aided simulation in surgery.

Despite the fact that computer-aided surgical planning and simulation is increasingly used in reconstructive surgery and trauma, the use of this technology in PO surgery is at the beginning. Several advantages have been reported in terms of the use of CASS in orthopaedic surgery [3-7,21,25]. The visuospatial understanding of the bony anatomy is enhanced by physical models, maybe because of the combination of both a tactile and an optic experience, which has been demonstrated to improve 
the execution of surgical procedures, especially in complex cases. We used intraoperative, sterile, true size 3D-printed models that, in some cases, allowed us to overcome the issues related to the limited visualization of the bony segments. CASS and 3D printed models may be crucial in case of arthroscopic or minimally invasive surgery, when only minimal parts of the bone can be inspected [18]. This aspect can stimulate surgeons to rehearse minimally invasive surgical approaches or arthroscopic techniques in a more precise and effective fashion.

Additionally, the combination of surgical simulation and 3D printing allows us to produce patient-specific guides and jigs, potentially reducing the surgical equipment during operation, or even produce custom implants that match perfectly with the patient's unique anatomy. In our experience, CASS enabled the prebending of the hardware and the customization of massive allografts. While the prebending of the hardware by CASS has been demonstrated to reduce surgical time and bleeding, a customized massive allograft is of special interest, since it can be produced preoperatively in a clean room environment, further reducing surgical time and potential infections caused by contamination of the graft during intraoperative preparation, and allowing us to save a single bone harvested from one donor for multiple implants. [26].

Furthermore, the potential combination of CASS and virtual reality could be used for surgical training in PO surgery, while animation could be useful for supporting patient education before surgery $[1,27]$.

However, CASS and additive manufacturing are often expensive and not easily available for routine clinical use, limiting their application only for research purposes in a few highly specialized centers and university hospitals. It is essential to underline that all software applications but one (Creo Parametric) utilized in our study were open source or free, and very light in terms of using computer resources. The 3D printer was a low-cost entry-level machine. This implies a drastic reduction in costs and the potential diffusion of this technological innovation into the routine clinical practice, improving the quality of care even in peripheral hospitals or in developing countries.

Our study must be seen in light of some limitations. First, we aimed to investigate the feasibility of an in-house low-cost CASS process on a small heterogeneous case series; thus, the study was not designed to assess CASS in terms of risk-benefits and cost-effectiveness, in comparison with traditional planning procedures. To this purpose, case control studies and prospective cohort studies are required in the near future. Second, the final correction was evaluated on plain radiographs, since we could not obtain postoperative CT scans from our patients, due to ethical issues. This prevented us from verifying the final correction in a 3D fashion that is more reliable. Third, PO surgery frequently regards the correction of immature bone with open physes. Despite the fact that the correction may be satisfactory at the time of surgery, recurrent deformities may present at follow-up, due to the abnormal growth of the physes. This issue could be overcome by the combination of corrective osteotomies and growth modulation procedures in staged, multistep surgeries, but the current technology is still far from including growth modulation in the CASS process. Fourth, the CASS process essentially involved the correction of the bones, thus, not considering the role of soft tissues. This issue implies that we could not simulate the surgical approach, the repair, transfer, or reconstruction of capsules or ligaments. Moreover, we superimposed rigid constraints, for example, in case of radial relocation in forearm deformities. In the future, the application of specific constraints mimicking the elastic modules of capsules, tendons, and ligaments will increase the accuracy and effectiveness of the CASS process.

\section{Conclusions}

Our study describes the application of a safe, effective, user-friendly, and low-cost CASS process in PO surgery. We are convinced that our study will stimulate the widespread implementation of this technological innovation in routine clinical practice, for the treatment of rare congenital and post-traumatic limb deformities during childhood. Future studies may demonstrate quantitative evidence of more reliable, effective, and time-efficient surgeries. The cost-effectiveness ratio should be tested in terms of improved patient outcomes and patient education. Further pilot studies, along with 
upcoming technological innovations, should compare different software, 3D printers, and materials, in order to implement more rapid, cheap, and user-friendly surgical simulation processes.

Author Contributions: Conceptualization, E.M. and G.T.; methodology, L.F.; software, G.M.S.; validation, G.M.S., F.N. and G.T.; formal analysis, E.M.; investigation, G.T. and G.L.D.G.; resources, S.S. (Stefano Stallone); data curation, F.N., P.P.; writing-original draft preparation, F.N., P.Z.; writing—review and editing, L.F., G.M.S. and G.T.; visualization, S.S. (Stefano Stilli); supervision, A.L.; project administration, A.L. All authors have read and agreed to the published version of the manuscript.

Funding: This research received no external funding.

Conflicts of Interest: The authors declare no conflict of interest.

\section{References}

1. Bae, D.S. Simulation in Pediatric Orthopaedic Surgery. J. Pediatr. Orthop. 2015, 35, S26-S29. [CrossRef] [PubMed]

2. Gateno, J.; Xia, J.J.; Teichgraeber, J.F.; Christensen, A.M.; Lemoine, J.J.; Liebschner, M.A.K.; Gliddon, M.J.; Briggs, M.E. Clinical Feasibility of Computer-Aided Surgical Simulation (CASS) in the Treatment of Complex Cranio-Maxillofacial Deformities. J. Oral Maxillofac. Surg. 2007, 65, 728-734. [CrossRef] [PubMed]

3. Xu, H.J.; Zhou, Y.X.; Chen, L.B.; Wang, J.W.; Kan, W.S.; Ma, D.Z. Simulated surgeries of acetabular reconstruction for high-dislocated hips. Chin. J. Exp. Surg. 2016, 33, 820-822.

4. Bao, H.D.; Yan, P.; Zhu, F.; Qiu, Y.; Zhu, Z.Z.; Wang, B.; Qian, B.P.; Yu, Y. Technology of pre-operative digitalized simulation of osteotomy in degenerative spinal deformity with sagittal malalignment. Chin. J. Orthop. 2016, 36, 321-328.

5. Zhang, Y.Z.; Lu, S.; Chen, B.; Zhao, J.M.; Liu, R.; Pei, G.X. Application of computer-aided design osteotomy template for treatment of cubitus varus deformity in teenagers: A pilot study. J. Shoulder Elb. Surg. 2011, 20, 51-56. [CrossRef]

6. Jiang, H.; Li, M.; Wu, Y. Application of computer simulation in the treatment of traumatic cubitus varus deformity in children. Medicine (Baltimore) 2019, 98, e13882. [CrossRef]

7. Takeyasu, Y.; Oka, K.; Miyake, J.; Kataoka, T.; Moritomo, H.; Murase, T. Preoperative, computer simulation-based, three-dimensional corrective osteotomy for cubitus varus deformity with use of a custom-designed surgical device. J. Bone Jt. Surg. Ser. A 2013, 95, e173. [CrossRef]

8. Frizziero, L.; Santi, G.M.; Liverani, A.; Giuseppetti, V.; Trisolino, G.; Maredi, E.; Stilli, S. Paediatric Orthopaedic Surgery with 3D Printing: Improvements and Cost Reduction. Symmetry 2019, 11, 1317. [CrossRef]

9. Osti, F.; Santi, G.; Neri, M.; Liverani, A.; Frizziero, L.; Stilli, S.; Maredi, E.; Zarantonello, P.; Gallone, G.; Stallone, S.; et al. CT Conversion Workflow for Intraoperative Usage of Bony Models: From DICOM Data to 3D Printed Models. Appl. Sci. 2019, 9, 708. [CrossRef]

10. InVesalius. Available online: https://invesalius.github.io/ (accessed on 18 April 2019).

11. MeshLab. Available online: https://www.meshlab.net/ (accessed on 20 April 2019).

12. Available online: http://www.meshmixer.com/ (accessed on 20 April 2019).

13. blender.org-Home of the Blender Project-Free and Open 3D Creation Software. Available online: https: //www.blender.org/ (accessed on 9 May 2019).

14. Software di Modellazione 3D Creo Parametric | PTC. Available online: https://www.ptc.com/it/products/ creo/parametric (accessed on 21 February 2019).

15. Di Gennaro, G.; Trisolino, G. Chronic Radial Head Dislocation Caused by Focal Fibrocartilaginous Dysplasia (FFCD) of the Ulna: A Case Report and Review of the Literature. EC Paediatr. 2018, 7, 312-314.

16. Miyake, J.; Murase, T.; Oka, K.; Moritomo, H.; Sugamoto, K.; Yoshikawa, H. Computer-assisted corrective osteotomy for malunited diaphyseal forearm fractures. J. Bone Jt. Surg. Ser. A 2012, 94, e150. [CrossRef]

17. Miyake, J.; Oka, K.; Kataoka, T.; Moritomo, H.; Sugamoto, K.; Murase, T. 3-dimensional deformity analysis of malunited forearm diaphyseal fractures. J. Hand Surg. Am. 2013, 38, 1356-1365. [CrossRef] [PubMed]

18. Colaris, J.W.; Oei, S.; Reijman, M.; Holscher, H.; Allema, J.H.; Verhaar, J.A.N. Three-dimensional imaging of children with severe limitation of pronation/supination after a both-bone forearm fracture. Arch. Orthop. Trauma Surg. 2014, 134, 333-341. [CrossRef] [PubMed]

19. Abe, S.; Oka, K.; Miyamura, S.; Shigi, A.; Tanaka, H.; Sugamoto, K.; Yoshikawa, H.; Murase, T. Three-Dimensional In Vivo Analysis of Malunited Distal Radius Fractures With Restricted Forearm Rotation. J. Orthop. Res. 2019, 37, 1881-1891. [CrossRef] [PubMed] 
20. de Freitas, L.F.P.; Barbieri, C.H.; Mazzer, N.; Zatiti, S.C.A.; Bellucci, Â.D.; Nogueira-Barbosa, M.H. Intraobserver and interobserver reliability of radial torsion angle measurements by a new and alternative method with computed tomography. Clinics 2010, 65, 1093-1097. [CrossRef] [PubMed]

21. Bockhorn, L.; Gardner, S.S.; Dong, D.; Karmonik, C.; Elias, S.; Gwathmey, F.W.; Harris, J.D. Application of three-dimensional printing for pre-operative planning in hip preservation surgery. J. Hip Preserv. Surg. 2019, 6, 164-169. [CrossRef]

22. Perica, E.; Sun, Z. Patient-specific three-dimensional printing for pre-surgical planning in hepatocellular carcinoma treatment. Quant. Imaging Med. Surg. 2017, 7, 668-677. [CrossRef]

23. Shen, S.; Wang, P.Z.; Li, X.Y.; Han, X.; Tan, H.L. Pre-operative simulation using a three-dimensional printing model for surgical treatment of old and complex tibial plateau fractures. Sci. Rep. 2020, 10, 1-11. [CrossRef]

24. Huang, J.H.; Liao, H.; Tan, X.Y.; Xing, W.R.; Zhou, Q.; Zheng, Y.S.; Cao, H.Y.; Zeng, C.J. Surgical treatment for both-column acetabular fractures using pre-operative virtual simulation and three-dimensional printing techniques. Chin. Med. J. (Engl.) 2020, 133, 395-401. [CrossRef]

25. Hung, C.C.; Li, Y.T.; Chou, Y.C.; Chen, J.E.; Wu, C.C.; Shen, H.C.; Yeh, T. Te Conventional plate fixation method versus pre-operative virtual simulation and three-dimensional printing-assisted contoured plate fixation method in the treatment of anterior pelvic ring fracture. Int. Orthop. 2019, 43, 425-431. [CrossRef]

26. Grassi, F.R.; Grassi, R.; Vivarelli, L.; Dallari, D.; Govoni, M.; Nardi, G.M.; Kalemaj, Z.; Ballini, A. Design techniques to optimize the scaffold performance: Freeze-dried bone custom-made allografts for maxillary alveolar horizontal ridge augmentation. Materials 2020, 13, 1393. [CrossRef] [PubMed]

27. Michalski, A.; Stopa, M.; Miśkowiak, B. Use of multimedia technology in the doctor- patient relationship for obtaining patient informed consent. Med. Sci. Monit. 2016, 22, 3994-3999. [CrossRef] [PubMed]

(C) 2020 by the authors. Licensee MDPI, Basel, Switzerland. This article is an open access article distributed under the terms and conditions of the Creative Commons Attribution (CC BY) license (http://creativecommons.org/licenses/by/4.0/). 